\title{
Microrna tuần hoàn - Dấu chứng sinh học tiềm năng cho chẩn đoán sớm bệnh thoái hóa khớp
}

\author{
Hồ Thị Bích Phượng ${ }^{1 *}$, Lê Thị Trúc Linh ${ }^{1}$, Lê Huyền Ái Thúy ${ }^{1}$ \\ ${ }^{1}$ Trường Đại học Mở Thành phố Hồ Chí Minh \\ *Tác giả liên hệ, Email: bichphuong.hth90@gmail.com
}

THÔNG TIN

DOI: $10.46223 / \mathrm{HCMCOUJS}$.

tech.vi.15.1.1018.2020

Ngày nhận: 25/05/2020

Ngày nhận lại: 21/07/2020

Duyệt đăng: 23/08/2020

Tù khóa:

chẩn đoán sớm, dấu chứng sinh học, microRNA tuần hoàn, thoái hóa khớp

Keywords:

biomarker, circulating microRNA, early diagnosis, osteoarthritis

\section{TÓM TÁ́T}

Thoái hóa khớp (THK) là dạng viêm khớp phổ biến nhất và là một trong những nguyên nhân chính gây ra các cơn đau ở khớp, làm giảm khả năng vận động và có thể dẫn đến tàn phế ở người. Chẩn đoán sớm THK là yếu tố quan trọng giúp cho việc điều trị bệnh hiệu quả. Tuy nhiên, các phương pháp chẩn đoán hiện nay không đủ nhạy để phát hiện các thay đổi trong giai đoạn sớm của bệnh. Vì vậy, việc tìm ra các dấu chứng sinh học (biomarker) có thể giúp phát hiện THK ở giai đoạn đầu cũng như theo dõi tiến triển của bệnh là rất cần thiết. Các nghiên cứu hiện nay đang chú ý đến phân tử microRNA (miRNA) tuần hoàn (circulating miRNA) nhờ các ưu điểm: không bị phân hủy bởi RNase, chịu được điều kiện khắc nghiệt (nhiệt độ cao, $\mathrm{pH}$ rất thấp hoặc rất cao), lưu trữ trong thời gian dài, chịu được việc đông lạnh-rã đông nhiều lần và lấy mẫu không cần phương pháp xâm lấn. Nhiều nghiên cứu đã cho thấy tiềm năng sử dụng miRNA tuần hoàn trong chẩn đoán sớm THK trong lâm sàng. Từ đó, chúng tôi tiến hành tổng hợp các dữ liệu nghiên cứu về miRNA tuần hoàn trong THK, làm cơ sở lý thuyết cho các nghiên cứu thực nghiệm sau này ở Việt Nam.

ABSTRACT
Osteoarthritis (OA) is the most common form of arthritis and
is one of the main causes of joint pain, impaired mobility and
physical disability. Early diagnosis of OA is an important factor
for effective treatment. However, current diagnostic methods are
not sensitive enough to detect changes in the initial stages of the
disease. Therefore, the identification of biomarker allows for
detection of OA at the early stage and monitor disease
progression. Current studies have focused on circulating
microRNA (miRNA) molecules due to many advantages: not
digest by RNase, withstand harsh conditions (boiling, very low
or high pH), store for long time, repeat freeze-thaw cycles and
take samples with non-invasive methods. Many studies showed
the potential of using circulating miRNA in the early diagnosis
of OA in clinical practice. Thus, we proceed to review the
research data of circulating miRNA in OA, as a theoretical basis
for later experimental studies in Vietnam.




\section{Thoái hóa khớp}

\subsection{Giới thiệu}

THK là bệnh phổ biến nhất trong tất cả các bệnh liên quan đến khớp, chiếm hơn $50 \%$ (Lane, Shidara, \& Wise, 2017). Bệnh thường xảy ra ở người cao tuổi, nhưng cũng có thể phát triển sớm ở người bị chấn thương khớp do lao động hoặc chơi thể thao hoặc ở người béo phì. Theo thống kê của Tổ chức $\mathrm{Y}$ tế Thế giới, ước tính trong dân số có khoảng $9,6 \%$ nam giới và $18 \%$ nữ giới trên 60 tuổi mắc các triệu chứng của bệnh THK (WHO). Tại Việt Nam, tuy chưa có số liệu thống kê chính xác nhưng tỷ lệ mắc bệnh THK ở người trên 40 tuổi cũng chiếm trên $23 \%$. THK gây ra các cơn đau nhức ở khớp, gây cứng khớp, khó khăn khi vận động và có thể dẫn đến tàn phế. $80 \%$ người mắc THK bị hạn chế khi vận động và $25 \%$ trong số đó không thể tự thực hiện một số hoạt động nặng hằng ngày trong cuộc sống $(\mathrm{WHO})$. Chính vì vậy, THK làm giảm chất lượng cuộc sống và tăng gánh nặng chi phí y tế cho người bệnh (Cuadra, González-Huerta, Romero-Cordoba, Hidalgo-Miranda, \& Miranda-Duarte, 2014; Lane et al., 2017).

\subsection{Các giai đọ̣n của THK}

THK là bệnh mãn tính, diễn tiến rất chậm. Trong một thời gian dài, bệnh nhân không có dấu hiệu rõ rệt của THK, chỉ có dấu hiệu sớm của thoái hóa sụn, viêm màng hoạt dịch và cấu trúc xương bị thay đổi ngay cả trước khi có các biểu hiện lâm sàng, dẫn đến phá hủy nghiêm trọng và suy giảm chức năng của các khớp (Goldring \& Goldring, 2010). Hơn thế nữa, THK bao gồm những thay đổi xảy ra trong toàn bộ khớp và làm ảnh hưởng đến hầu hết các mô chính của khớp (sụn, xương dưới sụn, dịch khớp, bao hoạt dịch) (Loeser, Goldring, Scanzello, \& Goldring, 2012). Tùy theo mức độ của các thay đổi trong khớp, THK được chia thành 4 giai đoạn dựa vào hình ảnh X-quang (Hình 1). Giai đoạn 1 là giai đoạn mà khe khớp gần như bình thường, sụn khớp chưa bị mòn, các chức năng hoạt động khớp cũng bình thường, chỉ có xuất hiện gai xương nhỏ, người bệnh chưa có biểu hiện bất thường. Đến giai đoạn 2 thì trên ảnh chụp X quang gai xương sẽ xuất hiện rõ hơn, khe khớp hơi hẹp, người bệnh có các biểu hiện đau khi vận động và khi nghỉ ngơi sẽ bớt đau hoặc bị cứng khớp vào buổi sáng. Giai đoạn 3 biểu hiện qua khe khớp bị hẹp khá rõ, xuất hiện nhiều gai xương có kích thước vừa và lớn, lớp sụn bao bọc đầu xương bị bào mòn nhiều, xương dưới sụn đặc hơn, bề mặt khớp có thể bị biến dạng. Giai đoạn 4 là giai đoạn bệnh nặng và nghiêm trọng, khe khớp hẹp nhiều, các gai xương có kích thước lớn, xương dưới sụn đặc, bề mặt khớp biến dạng rõ ràng (Kellgren \& Lawrence, 1957).

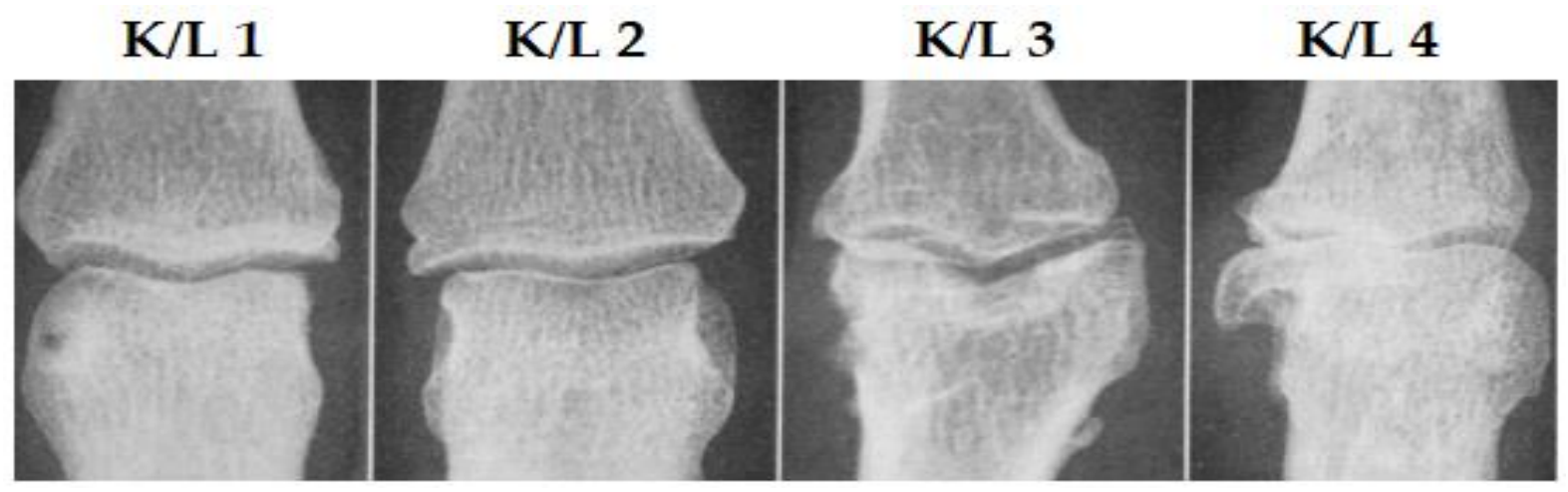

Hình 1. Hình chụp X-quang bốn giai đoạn của THK

Ghi chú: K/L: Kellgren và Lawrence (1957)

\subsection{Nguyên nhân gây THK}

Các nguyên nhân gây ra bệnh THK hiện nay chia thành hai loại: nguyên phát và thứ phát. Nguyên nhân nguyên phát là nguyên nhân chính gây ra THK, do quá trình tổng hợp và thoái hóa 
cấu trúc sụn và xương dưới sụn bị mất đi sự cân bằng (Sharma, Jagga, Lee, \& Nam, 2013). Các trường hợp THK do nguyên nhân nguyên phát gây ra bao gồm: người cao tuổi (tỷ lệ mắc bệnh tăng theo độ tuổi), nội tiết của cơ thể thay đổi (mãn kinh, bị đái tháo đường,...) làm tăng nguy cơ mắc bệnh, người sinh ra trong gia đình có người đã bị THK thì nguy cơ mắc bệnh cao hơn. Nguyên nhân thứ hai là nguyên nhân thứ phát, có thể gặp ở mọi lứa tuổi, bao gồm: giới tính và hormone (nữ giới mắc bệnh THK nhiều hơn ở nam giới do nội tiết thay đổi khi lớn tuổi); bị các chấn thương liên quan đến xương khớp như: rách dây chằng, tổn thương sụn, viêm bao hoạt dịch hoặc gân bánh chè, gãy xương khớp,... sẽ dễ dẫn đến THK; béo phì (người béo phì hoặc tăng cân quá nhanh làm tăng áp lực lên vùng xương khớp, qua thời gian dài sẽ làm xương khớp bị đè nén và biến dạng dẫn đến THK), dinh dưỡng (một trong những nguyên nhân góp phần tăng nguy cơ THK là thiếu vitamin $\mathrm{D}$ ), nguyên nhân bẩm sinh (một số người có thể bị dị tật về khớp khi mới sinh ra như khớp gối quay ra ngoài hoặc quay vào trong, khớp gối quá duỗi cũng dẫn đến THK) và các tổn thương khác (viêm khớp dạng thấp, bệnh gout, chảy máu trong khớp).

\section{4. Điều trị THK}

Hiện nay vẫn chưa có phương pháp điều trị THK hiệu quả. Liệu pháp điều trị cho THK chủ yếu tập trung giúp bệnh nhân giảm đau và làm chậm sự tiến triển của bệnh. Phương pháp điều trị nội khoa chủ yếu là dùng thuốc giảm đau, làm vật lý trị liệu (chườm nóng, suối khoáng,...) hoặc cấy ghép tế bào gốc. Phương pháp điều trị ngoại khoa gồm có: nội soi cắt lọc và rửa khớp; khoan kích thích để tạo xương và cấy ghép tế bào sụn. Nếu bệnh nhân đến giai đoạn cuối THK thì sẽ bị chỉ định tháo khớp hoặc thay bằng khớp nhân tạo.

\subsection{Chẩn đoán THK}

Để việc điều trị bệnh đạt hiệu quả, bệnh nhân cần phải được chẩn đoán và tiếp nhận điều trị ở giai đoạn càng sớm càng tốt. Tiêu chuẩn vàng trong chẩn đoán bệnh THK hiện nay là dựa vào các triệu chứng lâm sàng và các thay đổi trên hình ảnh chụp X-quang (Beyer et al., 2015). Tuy nhiên, chụp X-quang chỉ có thể phát hiện được một số đặc điểm bệnh lý ở giai đoạn cuối của THK như xơ cứng xương, hình thành gai xương. Chụp X-quang không phát hiện được các tổn thương liên quan đến các mô khác như sụn, dây chằng hoặc các thay đổi xảy ra trong dịch khớp. Ngày nay, chụp cộng hưởng từ (MRI) được sử dụng như một công cụ hình ảnh nhạy hơn trong việc phát hiện tốt hơn các tổn thương xảy ra trong khớp như tổn thương hoặc thoái hóa vùng sụn, tổn thương tủy xương, rách sụn chêm. Mặc dù vậy, MRI vẫn chưa thể phát hiện THK ở giai đoạn sớm và chi phí sử dụng MRI cũng rất cao nên khó sử dụng phổ biến trong chẩn đoán cũng như hỗ trợ điều trị (Menashe et al., 2012).

Trong THK, các thay đổi trong quá trình trao đổi chất xảy ra từ trước khi có sự thay đổi về cấu trúc (thay đổi về cấu trúc là giai đoạn sau của $T H K$, dẫn đến các dấu hiệu lâm sàng rõ ràng cho bệnh, có thể phát hiện bệnh bằng chẩn đoán hình ảnh). Dựa trên đặc điểm này, các dấu chứng từ máu hoặc từ các mô của khớp (đã trải qua những thay đổi trong trao đổi chất) có thể cung cấp thông tin giá trị để chẩn đoán THK ở giai đoạn sớm (Nguyen et al., 2017), hay còn gọi là dấu chứng sinh hóa (biochemical marker). Mặc dù được mong đợi nhiều nhưng hàng loạt các dấu chứng sinh hóa liên quan đến sự trao đổi chất của xương và sụn đã được nghiên cứu lại không cho thấy sự cải thiện đáng kể trong việc dự đoán sớm THK (Schett et al., 2009) và không có dấu chứng sinh hóa nào được ứng dụng trong lâm sàng. Vì vậy, việc tìm ra các dấu chứng sinh học khác có thể chẩn đoán nhanh, nhạy, giúp phát hiện THK ở giai đoạn đầu của bệnh và có thể theo dõi tiến triển của bệnh là rất cần thiết. 


\section{MicroRNA}

MicroRNA (miRNA) là các RNA nhỏ có kích thước từ 18 đến 25 nucleotide, có chức năng điều hòa biểu hiện của các gen sau phiên mã bằng cách gắn đặc hiệu lên một trình tự đặc biệt có trên mRNA đích (Ambros, 2004; Bartel, 2004). Có khoảng 38.589 miRNAs đã được tìm thấy ở người (www.mirbase.org, release 22.1, 2018). Theo các chương trình bioinformatics dự đoán, ở người có hơn 50\% các gen mã hóa được điều hòa bởi miRNA (C. Chen et al., 2005; Lewis, Burge, \& Bartel, 2005). Đồng thời, trình tự miRNA ở các loài khác nhau được bảo tồn tiến hóa (He \& Hannon, 2004). Điều này chứng tỏ, miRNA có chức năng quan trọng. Năm 1981, lin-4 ở tuyến trùng Caenorhabditis elegans là phân tử miRNA đầu tiên được phát hiện (Chalfie, Horvitz, \& Sulston, 1981). Phân tử miRNA thứ hai là let-7 cũng được tìm thấy sau đó ở $\mathrm{C}$. elegans (Reinhart et al., 2000). Năm 2001, nhóm các RNA nhỏ, không mã hóa và có chức năng điều hòa biểu hiện gen này được gọi chung bằng thuật ngữ "microRNA".

MiRNA được tạo ra qua nhiều bước (Hình 2). Đầu tiên, các miRNA được phiên mã từ gen miRNA nằm trên DNA bởi phức hợp RNA polymerase II (Y. Lee et al., 2004). Hầu hết các miRNA được biết hiện nay được mã hóa bởi trình tự DNA nằm trong vùng intron của các gen mã hóa cho protein. Một số ít miRNA được mã hóa bởi trình tự DNA nằm trong vùng exons hoặc vùng không mã hóa (Rodriguez, Griffiths-Jones, Ashurst, \& Bradley, 2004). Quá trình phiên mã này sẽ tạo ra phân tử miRNA cơ sở (primary miRNA), mang nhiều cấu trúc kẹp tóc của nhiều miRNA khác nhau nằm liền kề (Kim, 2005; Y. Lee, Jeon, Lee, Kim, \& Kim, 2002). Sau đó, phức hợp enzyme Drosha (một loại RNAse II) và cofactor DGCR8 sẽ cắt rời các cấu trúc kẹp tóc trên miRNA cơ sở, tạo ra các tiền miRNA (precursor miRNA) với kích thước khoảng 70-100 nucleotide (Han et al., 2004; Y. Lee et al., 2003). Cả hai quá trình tạo miRNA cơ sở và tiền miRNA đều được thực hiện trong nhân tế bào. Tiếp đó, tiền miRNA được vận chuyển từ nhân tế bào qua màng nhân để ra ngoài tế bào chất nhờ Exportin-5 (Yi, Qin, Macara, \& Cullen, 2003). Sau khi ra ngoài tế bào chất, tiền miRNA được enzyme Dicer (một loại RNAse III) cắt thành phân tử RNA mạch đôi: một mạch là miRNA và mạch còn lại có trình tự bổ sung với trình tự miRNA (Chendrimada et al., 2005; Ketting et al., 2001). Helicase tiếp tục tháo xoắn RNA mạch đôi này thành hai mạch RNA đơn. Mạch miRNA sẽ tương tác với phức hợp RISCs chứa protein Arganaute (Ago-2) để gắn lên vùng 3' không mã hóa (3'UTR) của mRNA đích, làm ức chế quá trình phiên mã và dịch mã của mRNA đích hoặc dẫn đến mRNA đích bị cắt bỏ. Còn mạch RNA bổ sung với miRNA sẽ bị loại bỏ (Bossé \& Simard, 2010; Hutvagner \& Simard, 2008).

Việc miRNA gắn được lên mRNA đích phụ thuộc rất nhiều vào trình tự "seed sequence" hay “seed site", là trình tự từ nucleotide thứ $2-8$ ở đầu 5 ' của phân tử miRNA (Lewis et al., 2005). MiRNA điều hòa sự biểu hiện của mRNA chủ yếu thông qua vùng 3'UTR và một số ít điều hòa qua vùng 5'UTR hoặc vùng mã hóa (I. Lee et al., 2009). Trường hợp miRNA gắn lên vùng mã hóa sẽ có hiệu quả ức chế dịch mã ít hơn so với các vùng khác. Ngoài vị trí của vùng seed site trên mRNA đích thì các yếu tố khác như: số lượng các seed site, cấu trúc mRNA đích, khoảng cách giữa các seed site đều ảnh hưởng đến khả năng ức chế biểu hiện gen của miRNA (Brennecke, Stark, Russell, \& Cohen, 2005). 


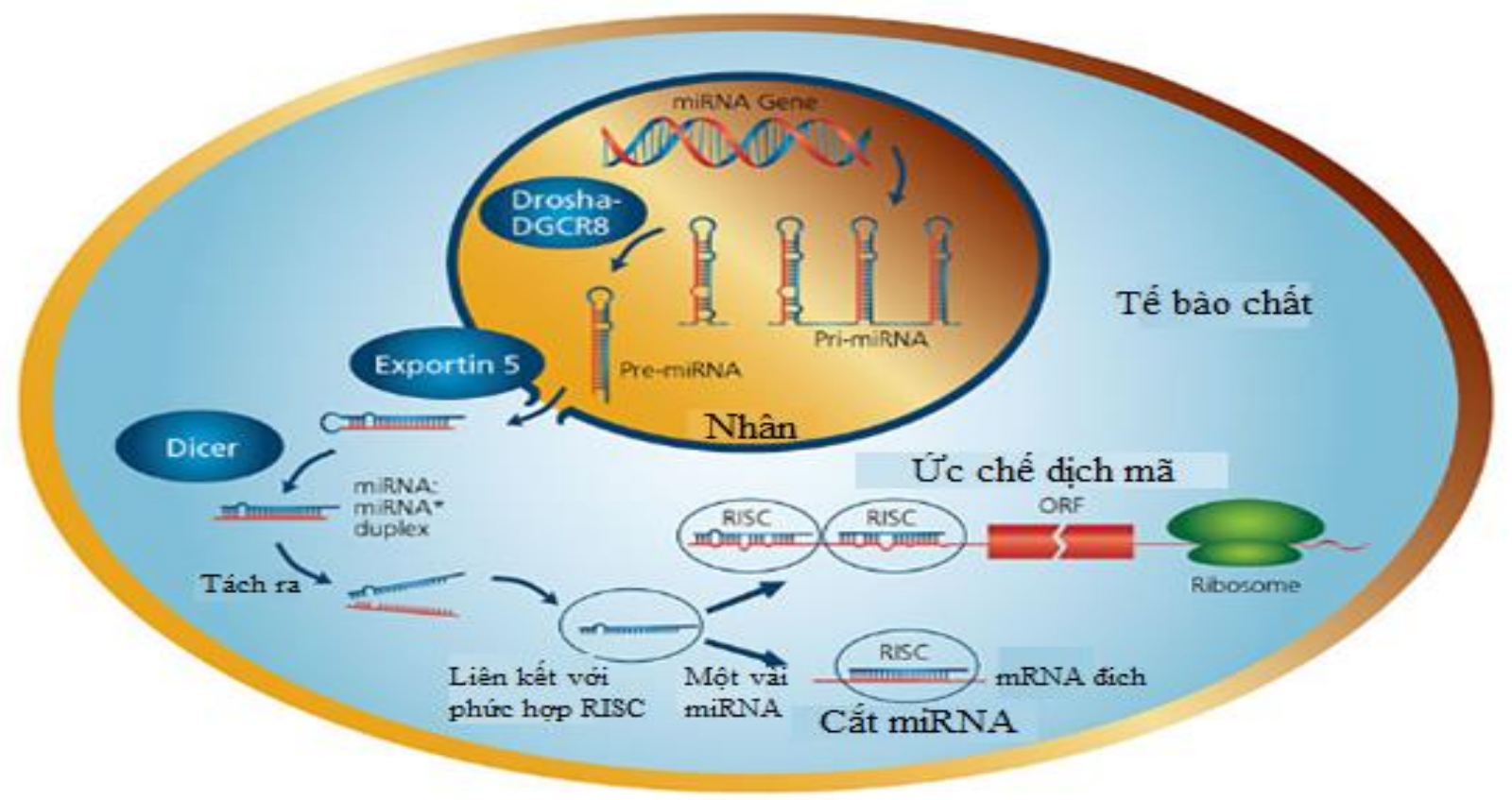

Hình 2. Quá trình trưởng thành của miRNA

Sự liên quan giữa miRNA với bệnh THK đã được chứng minh thông qua rất nhiều nghiên cứu khác nhau (Akhtar et al., 2010; Díaz-Prado et al., 2012; Iliopoulos, Malizos, Oikonomou, \& Tsezou, 2008; Jones et al., 2009; Kim et al., 2010; Le et al., 2016; Miyaki et al., 2009; Miyaki et al., 2010; Nakamura, Inloes, Katagiri, \& Kobayashi, 2011; Tardif, Hum, Pelletier, Duval, \& Martel-Pelletier, 2009). Tuy nhiên, các nghiên cứu mới nhất hiện nay lại đang chú ý đến miRNA tuần hoàn.

\section{MiRNA tuần hoàn}

MiRNA tuần hoàn là các miRNA được phát hiện trong các dịch ngoại bào của cơ thể như huyết tương, huyết thanh, dịch hoạt khớp, nước tiểu hoặc nước bọt (Hình 3) (Chim et al., 2008; Cortez et al., 2011; Hanke et al., 2010; Murata et al., 2010). Nguồn gốc và chức năng sinh học của microRNA tuần hoàn vẫn chưa được hiểu rõ. Có một số bằng chứng cho rằng miRNA tuần hoàn có thể được di chuyển trong hệ tuần toàn nhờ các bóng vận chuyển nhỏ (microvesicles), exosomes, phức hợp Ago protein hoặc HDL (high density lipoprotein) (Hình 3) (Vickers, Palmisano, Shoucri, Shamburek, \& Remaley, 2011). MicroRNA tuần hoàn có thể là sản phẩm phụ của tế bào hoặc là phân tử trung gian trong con đường truyền tín hiệu phản ánh tình trạng bệnh lý của tế bào (Turchinovich, Samatov, Tonevitsky, \& Burwinkel, 2013). Sự thay đổi trong mức độ biểu hiện của phân tử miRNA tuần hoàn với bệnh cùng với đặc điểm rất bền khi lưu thông trong máu, thời gian bán rã dài (khoảng 5 ngày trong huyết thanh) (Gantier et al., 2011), không bị phân hủy bởi Rnase, có thể duy trì ổn định ở nhiệt độ phòng và trong các điều kiện bất lợi của việc giải đông nhiều lần (X. Chen et al., 2008; Mitchell et al., 2008), đặc biệt là việc lấy mẫu không gây xâm lấn ở bệnh nhân, làm cho miRNA tuần hoàn trở thành phân tử tiềm năng trong chẩn đoán sớm và điều trị bệnh. 

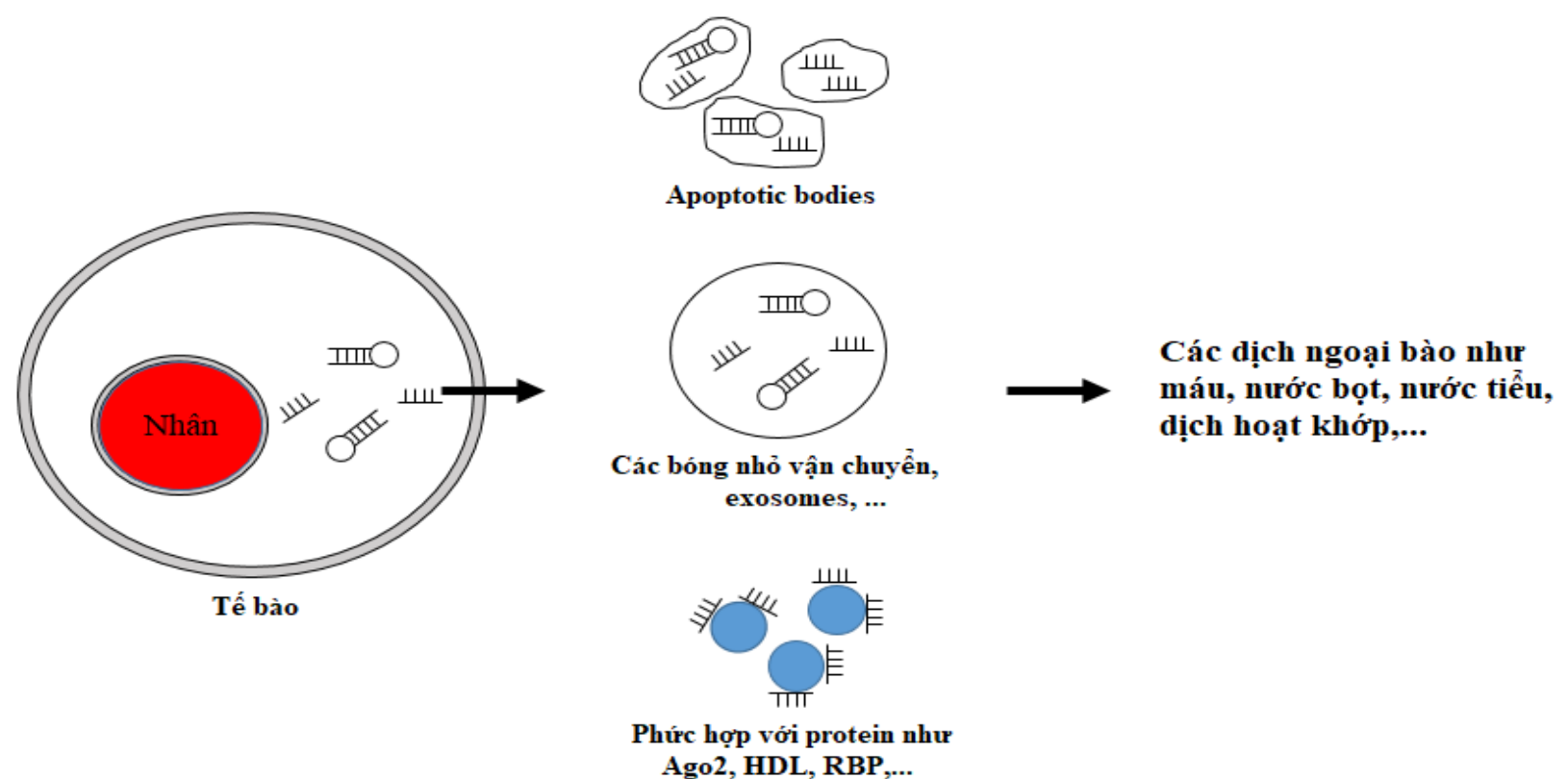

Hình 3. Cách vận chuyển microRNA tuần hoàn

Một số nghiên cứu đã chỉ ra rằng miRNA tuần hoàn có thể là một dấu chứng sinh học hỗ trợ chẩn đoán hữu hiệu cho nhiều bệnh ở người. Cả hai loại tiểu đường tuýp 1 và tuýp 2 đều có liên quan đến những thay đổi về profile miRNA trong máu. Những thay đồi này đôi khi có thể được phát hiện vài năm trước khi biểu hiện bệnh. Hơn thế nữa, mức độ biểu hiện của một số miRNA nhất định có thể dùng để dự đoán các biến chứng lâu dài của bệnh (Guay \& Regazzi, 2013). MiRNA tuần hoàn cũng được dự đoán là dấu chứng sinh học quan trọng cho nhiều bệnh liên quan đến sự lão hóa ở người như: bệnh tim mạch, ung thư, viêm khớp, Alzheimer, đục thủy tinh thể, loãng xương, cao huyết áp, Parkinson, Huntington (Kumar, Vijayan, Bhatti, \& Reddy, 2017).

\section{MicroRNA tuần hoàn và bệnh thoái hóa khớp}

Vai trò và mối liên quan giữa mức độ biểu hiện các miRNA với bệnh THK đã được rất nhiều nghiên cứu chứng minh (Akhtar et al., 2010; Díaz-Prado et al., 2012; Iliopoulos, Malizos, Oikonomou, \& Tsezou, 2008; Jones et al., 2009; Kim et al., 2010; Le et al., 2016; Miyaki et al., 2009; Miyaki et al., 2010; Nakamura et al., 2011; Tardif, Hum, Pelletier, Duval, \& MartelPelletier, 2009). Tuy nhiên, các nghiên cứu này tập trung vào các miRNA biểu hiện trong tế bào sụn, khi lấy mẫu cần phụ thuộc vào phẫu thuật, khó khăn khi lấy mẫu cho chẩn đoán lâm sàng. Vì vậy, các nghiên cứu hiện nay cũng chuyển sang phân tử miRNA tuần hoàn để phát triển các dấu chứng sinh học tiềm năng cho chẩn đoán sớm bệnh THK.

Trong số các dịch cơ thể, các nghiên cứu về miRNA tuần hoàn thường sử dụng mẫu huyết thanh hoặc huyết tương nhờ tính không xâm lấn khi lấy mẫu. Nồng độ miR-132 trong huyết tương của bệnh nhân THK được tìm thấy giảm đáng kể so với người bình thường (Murata et al., 2010). Theo nghiên cứu của Cuadra et al. (2014), khi xác định mức độ biểu hiện của 380 miRNA trong huyết tương của bệnh nhân THK ở giai đoạn đầu của bệnh, có 12 miRNA biểu hiện quá mức so với người bình thường bao gồm miR-16, miR-20b, miR-19c, miR-30b, miR-93, miR-126, miR146a, miR-184, miR-186, miR-195, miR-345 và miR-885-5p (Cuadra et al., 2014). Ngoài ra, trong một nghiên cứu kéo dài 5 năm ở bệnh nhân THK gối và khớp hông phát hiện ra rằng ba miRNA (let-7e, miR-454 và miR-885-5p) có liên quan đến THK gối và hông ở giai đoạn cuối. Trong đó, mức độ biểu hiện của let-7e và miR-454 giảm, miRNA-885-5p tăng ở giai đoạn cuối của bệnh 
(Beyer et al., 2015). Năm 2017, Ntoumou et al. thực hiện microarray, so sánh 2.549 miRNA trong mẫu huyết thanh của 12 mẫu bệnh nhân THK và 12 mẫu bình thường. Kết quả có 279 miRNA biểu hiện bất thường: 205 miRNA tăng và 74 miRNA giảm ở mẫu THK so với mẫu bình thường (Ntoumou et al., 2017). Các phân tích tin-sinh học chỉ ra 77 miRNA có đích tác động thuộc các con đường tín hiệu liên quan đến THK. Tiếp đó, nhóm tác giả sử dụng Realtime-PCR để kiểm tra 7 miRNA trong số 77 miRNA, thì ghi nhận có 3 miRNA giảm biểu hiện rõ ràng ở bệnh nhân THK là: miR-33b-3p, miR-140-3p và miR-671-3p (Ntoumou et al., 2017). Cũng trong năm 2017, Kong, Gao, Si, và Zhao thực hiện một nghiên cứu tương tự, sử dụng kỹ thuật microarray để so sánh mức độ biểu hiện của các miRNA trong mẫu huyết tương của 8 bệnh nhân THK và 8 mẫu đối chứng bình thường. Kết quả có 41 miRNA tăng và 29 miRNA giảm trong mẫu THK so với đối chứng. Kiểm tra 8 miRNA có mức biểu hiện khác biệt nhất bằng Realtime-PCR, nhóm tác giả ghi nhận 3 miRNA là miR-19b-3p, miR-122-5p và miR-486-5p tăng đáng kể ở mẫu THK và có tiềm năng sử dụng làm dấu chứng sinh học cho chẩn đoán sớm bệnh (Kong et al., 2017; Skrzypa et al., 2019), sử dụng phương pháp Realtime-PCR để kiểm tra mức độ biểu hiện của 18 miRNA trong sụn và huyết thanh của 28 bệnh nhân THK, so sánh với 2 mẫu đối chứng bình thường. Kết quả cho thấy, miR-146a-5p tăng biểu hiện ở cả sụn và huyết thanh của bệnh nhân THK so với người bình thường (Skrzypa et al., 2019). Tóm lại, miRNA tuần hoàn có thể là một dấu chứng sinh học tiềm năng cho chẩn đoán sớm bệnh THK.

Ngày nay, càng có nhiều nghiên cứu xác định và phát triển các dấu ấn sinh học mới cho THK (Nguyen et al., 2017). Hiện một số dấu chứng sinh học đáng tin cậy cho THK đang được khảo sát khả năng áp dụng trong lâm sàng (Kraus et al., 2015). Nhiều ý kiến đề nghị sàng lọc cùng lúc nhiều dấu chứng sinh học bắt nguồn từ các mô khác nhau để kiểm tra những thay đổi trao đồi chất trong các mô khác nhau của khớp từ đó có thể xây dựng một phát đồ điều trị viêm khớp trong tương lai cho từng cá nhân. Như vậy, sử dụng dấu ấn sinh học trong chẩn đoán THK sẽ giúp các bác sĩ không chỉ phát triển một chiến lược điều trị THK ở giai đoạn sớm mà còn giúp giảm chi phí điều trị cho bệnh nhân.

\section{Kết luận và kiến nghị}

MicroRNA tuần hoàn là một dấu chứng sinh học rất tiềm năng, có thể ứng dụng trong lâm sàng để chẩn đoán sớm bệnh THK. Từ đó, làm tăng hiệu quả điều trị cũng như giảm chi phí y tế cho người bệnh. Tuy nhiên, các nghiên cứu khác nhau lại cho kết quả về loại miRNA liên quan đến THK khác nhau. Không có sự lặp lại về kết quả giữa các công bố kể trên nên rất khó để chọn ra những miRNA tiềm năng làm dấu chứng sinh học cho chẩn đoán sớm THK. Nhờ sự phát triển của các công nghệ sinh học phân tử mới, các nghiên cứu sau này có thể hướng đến sử dụng kỹ thuật next generation sequencing (NGS) để có một "profile" đầy đủ về tất cả các miRNA hiện diện trong mẫu $\mathrm{THK}$ và mẫu bình thường để làm cơ sở và nền tảng cho những nghiên cứu tiếp theo.

\section{LÒ̀I CẢM ƠN} MBS-11.

Nghiên cứu này được thực hiện với sự tài trợ của Bộ Giáo dục và Đào tạo, mã số B2019-

\section{Tài liệu tham khảo}

Akhtar, N., Rasheed, Z., Ramamurthy, S., Anbazhagan, A. N., Voss, F. R., \& Haqqi, T. M. (2010). MicroRNA-27b regulates the expression of matrix metalloproteinase 13 in human osteoarthritis chondrocytes. Arthritis \& Rheumatism, 62(5), 1361-1371. doi:10.1002/art.27329

Ambros, V. R. (2004). The functions of animal microRNAs. Nature, 431(7006), 350-355. 
doi:10.1038/nature02871

Bartel, D. P. (2004). MicroRNAs: Genomics, biogenesis, mechanism, and function. Cell, 116(2), 281-297. doi:10.1016/S0092-8674(04)00045-5

Beyer, C., Zampetaki, A., Lin, N.-Y., Kleyer, A., Perricone, C., Iagnocco, A., . . Kiechl, S. (2015). Signature of circulating microRNAs in osteoarthritis. Annals of the Rheumatic Diseases, 74(3), 1-7. doi:10.1136/annrheumdis-2013-204698

Bossé, G. D., \& Simard, M. J. (2010). A new twist in the microRNA pathway: Not dicer but argonaute is required for a microRNA production. Cell Research, 20(7), 735-737. doi:10.1038/cr.2010.83

Brennecke, J., Stark, A., Russell, R. B., \& Cohen, S. M. (2005). Principles of MicroRNA-Target recognition. PLoS Biology, 3(3), 404-418. doi:10.1371/journal.pbio.0030085

Chalfie, M., Horvitz, H. B., \& Sulston, J. E. (1981). Mutations that lead to reiterations in the cell lineages of C. elegans. Cell, 24(1), 59-69. doi:10.1016/0092-8674(81)90501-8

Chen, C., Ridzon, D. A., Broomer, A. J., Zhou, Z., Lee, D. H., Nguyen, J. T., ...Guegler, K. J. (2005). Real-time quantification of microRNAs by stem-loop RT-PCR. Nucleic Acids Research, 33(20), 179-188. doi:10.1093/nar/gni178

Chen, X., Ba, Y., Ma, L., Cai, X., Yin, Y., Wang, K., ...Zhang, C.-Y. (2008). Characterization of microRNAs in serum: A novel class of biomarkers for diagnosis of cancer and other diseases. Cell Research, 18(10), 997-1006.

Chendrimada, T. P., Gregory, R. I., Kumaraswamy, E., Norman, J., Cooch, N., Nishikura, K., \& Shiekhattar, R. (2005). TRBP recruits the Dicer complex to Ago2 for microRNA processing and gene silencing. Nature, 436(7051), 740-744. doi:10.1038/nature03868

Chim, S. S. C., Shing, T. K. F., Hung, E. C. W., Leung, T.-y., Lau, T.-k., Chiu, R. W. K., \& Lo, Y. M. D. (2008). Detection and characterization of placental microRNAs in maternal plasma. Clinical Chemistry, 54(3), 482-490. doi:10.1373/clinchem.2007.097972

Cortez, M. A., Bueso-Ramos, C. E., Ferdin, J., Lopez-Berestein, G., Sood, A. K., \& Calin, G. A. (2011). MicroRNAs in body fluids - The mix of hormones and biomarkers. Nature Reviews Clinical Oncology, 8(8), 467-477. doi:10.1038/nrclinonc.2011.76

Cuadra, V. M. B., González-Huerta, N. C., Romero-Cordoba, S., Hidalgo-Miranda, A., \& Miranda-Duarte, A. (2014). Altered expression of circulating microRNA in plasma of patients with primary osteoarthritis and in silico analysis of their pathways. PloS One, 9(6), 1-8. doi:10.1371/journal.pone.0097690

Díaz-Prado, S., Cicione, C., Muiños-López, E., Hermida-Gómez, T., Oreiro, N., Fernández-López, C., \& Blanco, F. J. (2012). Characterization of microRNA expression profiles in normal and osteoarthritic human chondrocytes. BMC Musculoskeletal Disorders, 13(1), 1-14. doi:10.1186/1471-2474-13-144

Gantier, M. P., McCoy, C. E., Rusinova, I., Saulep, D., Wang, D., Xu, D., ...Williams, B. R. G. (2011). Analysis of microRNA turnover in mammalian cells following Dicer1 ablation. Nucleic Acids Research, 39(13), 5692-5703. doi:10.1093/nar/gkr148

Goldring, M. B., \& Goldring, S. R. (2010). Articular cartilage and subchondral bone in the pathogenesis of osteoarthritis. Annals of the New York Academy of Sciences, 1192(1), 230237. doi:10.1111/j.1749-6632.2009.05240.x 
Guay, C., \& Regazzi, R. (2013). Circulating microRNAs as novel biomarkers for diabetes mellitus. Nat Rev Endocrinol, 9(9), 513-521.

Han, J., Lee, Y., Yeom, K.-H., Kim, Y.-K., Jin, H., \& Kim, V. N. (2004). The Drosha-DGCR8 complex in primary microRNA processing. Genes \& Development, 18(24), 3016-3027. doi:10.1101/gad.1262504

Hanke, M., Hoefig, K., Merz, H., Feller, A. C., Kausch, I., Jocham, M. D., ...Sczakiel, G. (2010). A robust methodology to study urine microRNA as tumor marker: MicroRNA-126 and microRNA-182 are related to urinary bladder cancer. Urologic Oncology: Seminars and Original Investigations, 28(6), 655-661.doi:10.1016/j.urolonc.2009.01.027

He, L., \& Hannon, G. J. (2004). MicroRNAs: Small RNAs with a big role in gene regulation. Nature Reviews Genetics, 5(7), 522-531. doi:10.1038/nrg1379

Hutvagner, G., \& Simard, M. J. (2008). Argonaute proteins: Key players in RNA silencing. Nature Reviews. Molecular Cell Biology, 9(1), 22-32.

Iliopoulos, D., Malizos, K. N., Oikonomou, P., \& Tsezou, A. (2008). Integrative microRNA and proteomic approaches identify novel osteoarthritis genes and their collaborative metabolic and inflammatory networks. PloS One, 3(11), 1-10. doi:10.1371/journal.pone.0003740

Jones, S. W., Watkins, G., Good, N. L., Roberts, S., Murphy, C. L., Brockbank, S. M. V., ...Newham, P. (2009). The identification of differentially expressed microRNA in osteoarthritic tissue that modulate the production of TNF- $\alpha$ and MMP13. Osteoarthritis and Cartilage, 17(4), 464-472. doi:10.1016/j.joca.2008.09.012

Kellgren, J. H., \& Lawrence, J. S. (1957). Radiological assessment of osteo-arthrosis. Annals of the Rheumatic Diseases, 16(4), 494-502. doi:10.1136/ard.16.4.494

Ketting, R. F., Fischer, S. E., Bernstein, E. J., Sijen, T., Hannon, G. J., \& Plasterk, R. H. A. (2001). Dicer functions in RNA interference and in synthesis of small RNA involved in developmental timing in C. elegans. Genes \& Development, 15(20), 2654-2659. doi:10.1101/gad.927801

Kim, V. N. (2005). MicroRNA biogenesis: Coordinated cropping and dicing. Nature Reviews. Molecular Cell Biology, 6(5), 376-385.

Kim, S. Y., Kim, A. Y., Lee, H. W., Son, Y. H., Lee, G. Y., Lee, J.-W., ...Kim, J. B. (2010). miR$27 \mathrm{a}$ is a negative regulator of adipocyte differentiation via suppressing PPAR $\gamma$ expression. Biochemical and Biophysical Research Communications, 392(3), 323-328. doi:10.1016/j.bbrc.2010.01.012

Kong, R., Gao, J., Si, Y., \& Zhao, D. (2017). Combination of circulating miR-19b-3p, miR-122$5 \mathrm{p}$ and miR-486-5p expressions correlates with risk and disease severity of knee osteoarthritis. American Journal of Translational Research, 9(6), 2852-2864.

Kraus, V. B., Blanco, F. J., Englund, M., Henrotin, Y., Lohmander, L. S., Losina, E., ...Persiani, S. (2015). OARSI clinical trials recommendations: Soluble biomarker assessments in clinical trials in osteoarthritis. Osteoarthritis Cartilage, 23(5), 686-697. doi:10.1016/j.joca.2015.03.002

Kumar, S., Vijayan, M., Bhatti, J. S., \& Reddy, P. H. (2017). MicroRNAs as peripheral biomarkers in aging and age-related diseases. Progress in Molecular Biology and Translational Science, 146, 47-94. doi:10.1016/bs.pmbts.2016.12.013 
Lane, N. E., Shidara, K., \& Wise, B. L. (2017). Osteoarthritis year in review 2016: Clinical. Osteoarthritis and Cartilage, 25(2), 209-215. doi:10.1016/j.joca.2016.09.025

Le, L. T. T., Swingler, T. E., Crowe, N., Vincent, T. L., Barter, M. J., Donell, S. T., ...Clark, I. M. (2016). The microRNA-29 family in cartilage homeostasis and osteoarthritis. Journal of Molecular Medicine, 94(5), 583-596. doi:10.1007/s00109-015-1374-Z

Lee, I., Ajay, S. S., Yook, J. I., Kim, H. S., Hong, S. H., Kim, N. H., ...Athey, B. D. (2009). New class of microRNA targets containing simultaneous 5'-UTR and 3'-UTR interaction sites. Genome Research, 19(7), 1175-1183. doi:10.1101/gr.089367.108

Lee, Y., Jeon, K., Lee, J.-T., Kim, S., \& Kim, V. N. (2002). MicroRNA maturation: Stepwise processing and subcellular localization. The EMBO Journal, 21(17), 4663-4670. doi:10.1093/emboj/cdf476

Lee, Y., Ahn, C., Han, J., Choi, H., Kim, J., Yim, J.,... Kim, V. N. (2003). The nuclear RNase III Drosha initiates microRNA processing. Nature, 425(6956), 415-419. doi:10.1038/nature01957

Lee, Y., Kim, M., Han, J., Yeom, K.-H., Lee, S., Baek, S. H., \& Kim, V. N. (2004). MicroRNA genes are transcribed by RNA polymerase II. The EMBO Journal, 23(20), 4051-4060. doi:10.1038/sj.emboj.7600385

Lewis, B. P., Burge, C. B., \& Bartel, D. P. (2005). Conserved seed pairing, often flanked by adenosines, indicates that thousands of human genes are microrna targets. Cell, 120(1), 1520. doi:10.1016/j.cell.2004.12.035

Loeser, R. F., Goldring, S. R., Scanzello, C. R., \& Goldring, M. B. (2012). Osteoarthritis: A disease of the joint as an organ. Arthritis Rheum, 64(6), 1697-1707. doi:10.1002/art.34453

Menashe, L., Hirko, K., Losina, E., Kloppenburg, M., Zhang, W., Li, L., \& Hunter, D. J. (2012). The diagnostic performance of MRI in osteoarthritis: A systematic review and metaanalysis. Osteoarthritis and Cartilage, 20(1), 13-21. doi:10.1016/j.joca.2011.10.003

Mitchell, P. S., Parkin, R. K., Kroh, E. M., Fritz, B. R., Wyman, S. K., Pogosova-Agadjanyan, E. L., ...Tewari, M. (2008). Circulating microRNAs as stable blood-based markers for cancer detection. Proc Natl Acad Sci USA, 105(30), 10513-10518. doi:10.1073/pnas.0804549105

Miyaki, S., Nakasa, T., Otsuki, S., Grogan, S. P., Higashiyama, R., Inoue, A., \& Asahara, H. (2009). MicroRNA-140 is expressed in differentiated human articular chondrocytes and modulates interleukin-1 responses. Arthritis \& Rheumatism, 60(9), 2723-2730. doi:10.1002/art.24745

Miyaki, S., Sato, T., Inoue, A., Otsuki, S., Ito, Y., Yokoyama, S., ...Asahara, H. (2010). MicroRNA-140 plays dual roles in both cartilage development and homeostasis. Genes \& Development, 24(11), 1173-1185. doi:10.1101/gad.1915510

Murata, K., Yoshitomi, H., Tanida, S., Ishikawa, M., Nishitani, K., Ito, H., \& Nakamura, T. (2010). Plasma and synovial fluid microRNAs as potential biomarkers of rheumatoid arthritis and osteoarthritis. Arthritis Research \& Therapy, 12(3), 1-14.

Nakamura, Y., Inloes, J. B., Katagiri, T., \& Kobayashi, T. (2011). Chondrocyte-specific microRNA-140 regulates endochondral bone development and targets Dnpep to modulate bone morphogenetic protein signaling. Molecular and Cellular Biology, 31(14), 3019-3028. doi:10.1128/MCB.05178-11 
Nguyen, L. T., Sharma, A. R., Chakraborty, C., Saibaba, B., Ahn, M.-E., \& Lee, S.-S. (2017). Review of prospects of biological fluid biomarkers in osteoarthritis. International Journal Molecular Sciences, 18(3), 1-19. doi:10.3390/ijms18030601

Ntoumou, E., Tzetis, M., Braoudaki, M., Lambrou, G., Poulou, M., Malizos, K., ...Tsezou, A. (2017). Serum microRNA array analysis identifies miR-140-3p, miR-33b-3p and miR-671$3 \mathrm{p}$ as potential osteoarthritis biomarkers involved in metabolic processes. Clinical Epigenetics, 9(1), 1-15. doi:10.1186/s13148-017-0428-1

Reinhart, B. J., Slack, F. J., Basson, M., Pasquinelli, A. E., Bettinger, J. C., Rougvie, A. E., ...Ruvkun, G. (2000). The 21-nucleotide let-7 RNA regulates developmental timing in Caenorhabditis elegans. Nature, 403(6772), 901-906.

Rodriguez, A., Griffiths-Jones, S., Ashurst, J. L., \& Bradley, A. (2004). Identification of mammalian microRNA host genes and transcription units. Genome Research, 14(10A), 1902-1910. doi:10.1101/gr.2722704

Schett, G., Kiechl, S., Bonora, E., Zwerina, J., Mayr, A., Axmann, R., ...Willeit, J. (2009). Vascular cell adhesion molecule 1 as a predictor of severe osteoarthritis of the hip and knee joints. Arthritis \& Rheumatism: Official Journal of the American College of Rheumatology, 60(8), 2381-2389. doi:10.1002/art.24757

Sharma, A. R., Jagga, S., Lee, S.-S., \& Nam, J.-S. (2013). Interplay between cartilage and subchondral bone contributing to pathogenesis of osteoarthritis. International Journal of Molecular Sciences, 14(10), 19805-19830. doi:10.3390/ijms141019805

Skrzypa, M., Szala, D., Gablo, N., Czech, J., Pajak, J., Kopanska, M., ...Zawlik, I. (2019). miRNA-146a-5p is upregulated in serum and cartilage samples of patients with osteoarthritis. Polski Przeglad Chirurgiczny, 91(3), 1-5. doi: 10.5604/01.3001.0013.0135

Tardif, G., Hum, D., Pelletier, J.-P., Duval, N., \& Martel-Pelletier, J. (2009). Regulation of the IGFBP-5 and MMP-13 genes by the microRNAs miR-140 and miR-27a in human osteoarthritic chondrocytes. BMC Musculoskeletal Disorders, 10(1), 1-11. doi:10.1186/14712474-10-148

Turchinovich, A., Samatov, T. R., Tonevitsky, A. G., \& Burwinkel, B. (2013). Circulating miRNAs: Cell-cell communication function? Front Genet, 4, 1-10. doi:10.3389/fgene.2013.00119/full

Vickers, K. C., Palmisano, B. T., Shoucri, B. M., Shamburek, R. D., \& Remaley, A. T. (2011). MicroRNAs are transported in plasma and delivered to recipient cells by high-density lipoproteins. Nature Cell Biology, 13(4), 423-433. doi:10.1038/ncb2210

Yi, R., Qin, Y., Macara, I., \& Cullen, B. R. (2003). Exportin-5 mediates the nuclear export of premicroRNAs and short hairpin RNAs. Genes \& Development, 17(24), 3011-3016. doi:10.1101/gad.1158803 